\title{
Aerial cable-car systems for public transport in low-income urban areas: lessons from Medellin, Colombia.
}

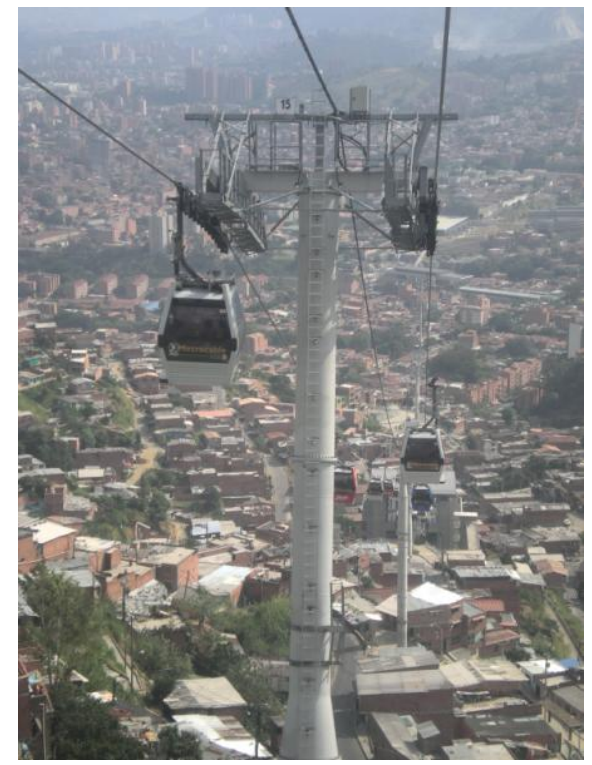

Peter Brand

School of Urban and Regional Planning Universidad Nacional de Colombia (Medellin Campus)

Medellin, Colombia

E: pbrand@unal.edu.co

Julio Davila

Development Planning Unit

University College London, UK

E: j.davila@ucl.ac.uk

Paper Presented in Track 11 (Transportation, Infrastructure and Planning) at the $3^{\text {rd }}$ World Planning Schools Congress, Perth (WA), 4-8 July 2011 


\title{
Aerial cable-car systems for public transport in low-income urban areas: lessons from Medellín, Colombia ${ }^{1}$
}

\begin{abstract}
In 2004 the first urban aerial cable-car public transport system was introduced in the city of Medellin, Colombia. The imaginative application of ski-slope technology to high-gradient, low-income urban areas attracted widespread attention from city authorities throughout Latin America, as well as Europe and Asia. However a second cable introduced in 2008 has had far less impact, confirming the suspicion that, to be worthwhile, cable-car systems require specific minimum conditions in terms of urban morphology and population density, as well as concerted complementary action by city authorities in order to ensure that mobility benefits help improve the living conditions, economic opportunities and social inclusion of the affected area populations. This paper outlines the technical and financial aspects of the cable-car systems employed in Medellin, and examines the urban conditions and planning considerations required to ensure the full integration and maximisation of social, economic and political benefits for catchment area populations, and provides pointers to successful application in other cities of the world.
\end{abstract}

Keywords: Aerial cable-car systems, public transport, urban improvement, mobility impacts, Medellin.

\section{Introduction}

In 2004 the first urban aerial cable-car public transport system was introduced in the city of Medellin, Colombia. The impact of the imaginative application of ski-slope technology to high-gradient, low-income urban areas has been considerable. As a relatively cheap, quick and highly visible response to urban transport problems, it has attracted widespread attention from city authorities throughout Latin America, as well as Europe and Asia. A similar system has already been built in Caracas and others are being developed in Rio de Janeiro and various cities in Colombia.

In the case of Medellin, whilst the first line has been highly successful, the impact of a second cable-car line inaugurated in 2008 suggests that, to be technically and economically worthwhile, cable-car systems require specific minimum conditions in terms of urban

\footnotetext{
${ }^{1}$ This paper is based on a current research project being undertaken by the Development Planning Unit, University College London in collaboration with the Universidad Nacional de Colombia (Medellin campus), and the Universidad de los Andes (Bogota). It is the first systematic appraisal of the pioneering experience of Medellin and looks to provide pointers for successful application in other cities of the world. An international workshop based on the results will be held in Medellin on the 12-14 of December of this year. Anyone interested should contact either of the authors. The research is funded by the UK Economic and Social Research Council and UKAid.
} 
morphology and population density, as well as careful articulation to the existing mass public transport network. Furthermore, considerable expectations revolved around the social benefits that the cable-cars would bring to the poor and marginalised urban areas where they have been implemented. The assumption has been that improved access and mobility options available to the poor would, per se, lead to improved opportunities and better living conditions.

While there is ample evidence to demonstrate that, in general terms, the lack of mobility is an integral part of the condition of disadvantage and deprivation (Social Exclusion Unit, 2002; Kenyon et al., 2006; Urry, 2007; Ohnmacht et al., 2009), it is far from clear that the opposite is true: that marginally improved mobility options for the poor lead directly and inexorably to social improvement. Recent sociological theorising (Kaufman et al. 2002, 2004) has emphasised the importance of context. In other words, although mobility is a generalised characteristic and requirement of contemporary society, how mobility options operate and are inserted into economic and social routines, the positive outcomes it produces and so on, depends on the specific conditions of any given community or social group.

The audacious decision to build cable-car systems in the poorest and most violent sectors of the city of Medellin was heavily influenced by these sorts of social consideration, initially in a intuitive way and later through more systematic planning. The analysis of the impact of the aerial cable-car systems in Medellin is therefore an excellent opportunity to test some underlying assumptions about the significance of mobility for the poor and to evaluate the planning policy and urban interventions which have accompanied them.

\section{The Medellin cable-cars in context}

In this section we briefly introduce the transport and planning history and events which set the scene for the urban cable-car systems, describe their technical and financial characteristics, and outline the urban contexts in which they operate, before concluding with some reflections on the questions of institutions, governance and political will and opportunism.

\section{Genesis}

The introduction of aerial cable-cars systems as part of the public transport infrastructure was undoubtedly an imaginative leap, with no urban precedent, some unmapped technical territory to negotiate and considerable local cynicism regarding the proposal. However, the 
materialization of the first cable-car system arose from a constellation of circumstances which not only explain the genesis of the project but also offer important signposts for the adoption of similar systems in other cities.

The first cable-car system, Line $\mathrm{K}$, was built in the poor and inaccessible northeastern sector of the city. This sector is characterised by a difficult, steeply sloping terrain broken by deep smaller valleys carved by the numerous streams running down the hillside to the main river. Developed through informal settlements and land invasions dating from the 1950s and '60s, by the end of the century it was the most densely urbanised sector of the city, with over 400 dwellings/hectare. As a consequence, road infrastructure was minimal and access difficult, although the area was relatively well served by conventional buses. The second cable-car line was to traverse a similar but more diverse physical and social landscape in the western sector of the city.

The accessibility problem was made even more evident when the city's overground Metro mass transport system was introduced in 1995. As the main Metro line (the only one in that sector of the city) runs parallel to the main river, a cable-car system was an attractive idea for bringing passengers down from the hillsides to the Metro system itself. The Metro authorities insist that this was always a socially-motivated project - a way of extending the benefits of the Metro to the poorest and more inaccessible areas of the city - but it also provided a way of increasing passenger numbers for a then underused Metro capacity. In the late 1990s various studies and technical consultations were undertaken by the Metro, so that by 2000 it had become a technically and financially feasible project.

Only the political moment of opportunity was needed. The year 2000 happened to be an electoral year, and the Metro de Medellin company presented the cable-car project to the mayoral candidates. Whilst most rejected it, the eventual winner, Luis Pérez (2001-2003), happened to be as keen an enthusiast of cable-cars as the newly-appointed head of the Metro de Medellin company. There was, as the (still) head of the Metro company describes, an 'alignment of the planets', and the new mayor immediately committed the city authorities; three years later it was in operation (personal interviews with Luis Pérez and Ramiro Márquez, General Manager of Metro de Medellin).

The speed with which the cable-car system was implemented and its articulation to the city's overall transport system owes much to the city's institutional and governance structure. The publically-owned Metro de Medellin company and the city authorities worked closely together in both a technical and financial sense, helped by the fact that the control of the Metro de Medellin company lies nominally in the hands of central government (arising 
from initial financial backing and eventual debt guarantee). Central government is in fact represented mainly by the local business and civic elite, which ensures a business ethic prevails over political expediency. Although this has led to periods of tension over technical matters (for example over bus feeder routes and a complementary rapid bus transit system currently under construction), these have generally been resolved on the basis of the efficiency of the Metro and a shared commitment to urban improvement.

\section{Technical and financial considerations}

There are currently three aerial cable-car lines in operation, two of which are urban public transport systems (Line K inaugurated in 2004 and Line $\mathrm{J}$ in 2008), along with a third Line $\mathrm{L}$ introduced in 2010 which connects with Line $\mathrm{K}$ as a tourist route to an ecological park on the edge of the city (see Table 1 and Figure 1).

Cable-car systems are relatively cheap and quick to construct, since they require little land acquisition and the technology is quite simple. In the case of the Medellin cable-cars, the first line (Line $\mathrm{K}, 2 \mathrm{~km}$.) cost in the region of US\$24 million, and the second (Line J, 2.8 $\mathrm{km}$.) around US\$47 million (at exchange rate values at the time). The cost per kilometer in urban areas compares favourably with RBT and rail systems. It should be remembered however that aerial cable-cars are not mass-transit systems and do not move more than 3.000 passengers per hour.

The cable car-system is a public sector project, financed jointly by the municipality and the Metro de Medellin, a publicly-owned company responsible for the building and operation of the city's metro system in operation since 1995. Modest construction costs make public sector capital borrowing quite feasible, but in the case of Medellin all three lines have been financed through normal capital investment budgets. The financial contribution of the Metro de Medellin company is based on the calculation of future returns accruing from increased passenger number using the Metro over a 10 to 15 -year period, and the difference is made up by the city authority in terms of social investment.

An important source of municipal finance for these and similar projects is the publiclyowned Empresas Públicas de Medellin, the city's large and efficient utilities company providing electricity generation and distribution, water and sewerage, waste disposal, telecommunications services. Statutorily, $30 \%$ of the company's profits go to the municipal authority, a sum equivalent to around US\$250 million in 2010. The Metro de Medellin claims to be one of the few metros to make an operating profit. It has a single tariff for any length of 
Table 1: Metrocables de Medellin - basic data

\begin{tabular}{|c|c|c|c|}
\hline & Line $\mathrm{K}$ & Line J & Line $\mathrm{L}$ \\
\hline Date of operation & August 2004 & March 2008 & February 2010 \\
\hline Construction time & 14 months & 15 months & 10 months \\
\hline Longitud & $2.072 \mathrm{~m}$ & $2.782 \mathrm{~m}$ & $4.469 \mathrm{~m}$ \\
\hline Commercial speed & $5 \mathrm{~m} / \mathrm{s}$ & $5 \mathrm{~m} / \mathrm{s}$ & $6 \mathrm{~m} / \mathrm{s}$ \\
\hline No. of supports & 20 & 31 & 25 \\
\hline No. of stations & 4 (incl.. Metro station) & 4 (incl. Metro station) & 2 \\
\hline $\begin{array}{l}\text { No. of cabins } \\
\text { (capacity } 10 \text { personas) }\end{array}$ & 93 & 119 & 27 \\
\hline Distance between cabins & $60 \mathrm{~m}$ & $60 \mathrm{~m}$ & $340 \mathrm{~m}$ \\
\hline Installed capacity & 3.000 passengers/hour & 3.000 passengers/hour & 1.200 passengers/hour \\
\hline $\begin{array}{l}\text { Estimated total cost } \\
\text { (US\$ 2003) }\end{array}$ & $\begin{array}{l}\text { US\$24 million } \\
\text { (at average } 2003 \\
\text { exchange rate) }\end{array}$ & $\begin{array}{l}\text { US\$ } 47 \text { million } \\
\text { (at average } 2007 \\
\text { exchange rate) }\end{array}$ & $\begin{array}{l}\text { US\$21 million } \\
\text { (at average } 2009 \\
\text { exchange rate) }\end{array}$ \\
\hline Cost per kilometre & US\$11.6 million & US $\$ 16.9$ millon & US\$ 4.7 million \\
\hline Finance & $\begin{array}{l}\text { Municipality: } 55 \% \\
\text { Metro: } 45 \%\end{array}$ & $\begin{array}{l}\text { Municipality: } 73 \% \\
\text { Metro: } 27 \%\end{array}$ & $\begin{array}{l}\text { Municipality: } 38 \% \\
\text { Metro: } 34 \% \\
\text { Regional Govt - 17\%; } \\
\text { Min. Transport - 9\%; Other -2\%. }\end{array}$ \\
\hline
\end{tabular}

Source: Metro de Medellín

journey, the single journey basic rate currently stands at Col\$1,750 (US\$0.97), the frequent travelers fare is Col\$1.450 (US\$0.80) and a combined metro-bus fare of Col $\$ 2,000$ (US\$1.10). The basic conventional bus fare is $\$ 1,500$ (US\$0.83). It is important to underline that the cable-cars (Lines $\mathrm{J}$ and $\mathrm{K}$ ) is part of the Metro system and therefore involves no additional cost for Metro users.

Map 1: The Metro system with Cable-cars (yellow dotted lies J and K)

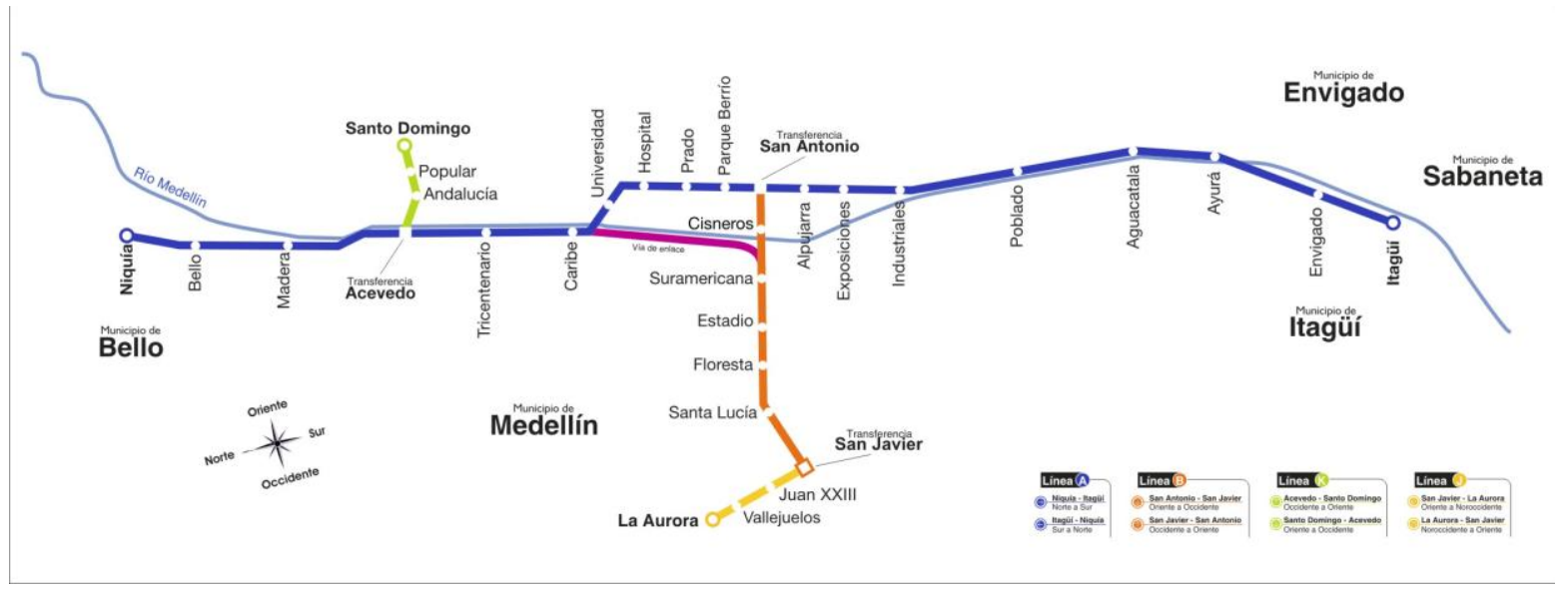

Source: Metro de Medellin 


\section{Cable-cars and urban crisis management}

The favourable 'alignment of the planets' also had much to do with the overall urban situation. During the 1980's Medellin emerged as the epicentre of Colombia's burgeoning illegal drugs trade and during the 90's became the world's most violent city (peaking at 381 murders/100.000 population in 1992), and many areas of the city were effectively ungovernable. At the same time the city was being forced to restructure its traditional manufacturing economy, and levels of poverty and unemployment were alarmingly high levels of (Brand, 2005).

It was in this context that the first cable-car system was conceived and implemented, and to which the following administration targeted as the focus of urban policy. The independent mayor Sergio Fajardo (2004-2007) proposed to cancel the city's 'historic debt' with those abandoned areas of the city, beginning with the sector of the first cable-car, the poorest and most violent of all (Davila, 2009). The first cable-car line became a prototype for subsequent interventions in the poor sectors of the city. A coherent and energetic policy of integrating the cable-car systems into the urban fabric through Integrated Urban Proyects (PUIs in their Spanish acronym form) was developed, centred around transport projects but aiming for urban improvement through a combined strategy on mobility, environment, housing and public space, and the goal of creating of new dynamic centres in previously atrophied sectors (Medellin-EDU, 2011).

The PUIs form part of a wider policy of urban improvement in the poor sectors of the city through the provision of park-libraries and new schools, a high public investment in the poorest sectors of the city which was to become formalised and widely acclaimed as the city's "social urbanism" (Echeverri and Orsini, 2010; The Architectural Review, 2011; Brand, 2010), although the social impact of specific projects is somewhat unclear (MacNamara, 2009; Blanco and Kobayashi, 2009; Cañon, 2010; Qunichía, 2011). Highquality architecture was also a central feature of this version of the Barcelona model of urban regeneration applied to low-income and informal housing areas in a developing country context.

How successful all this has been, and how sustainable it will be, is far from clear. Dealing with the illegal drugs organizations has been only 'half a miracle' (Fukuyama and Colby, 2011), urban violence has increased in recent years, reinvented gangs control the 'barrios', and intra-urban forced migration has grown alarmingly (El Tiempo, 2011). It is quite clear from the above that any assessment of the impact of increased mobility on the living 
conditions of the local population is a complex and multifaceted issue. As important as the transport system itself are the urban context and the set of urban interventions. With this in mind in the following section we outline some of the conceptual and methodological considerations developed during our research.

\section{Photo 1: Line K}

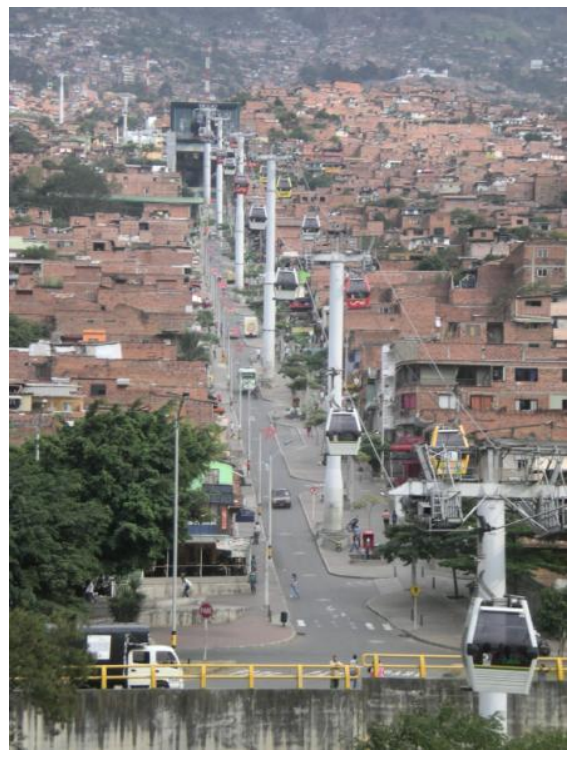

Photo 2: Line J

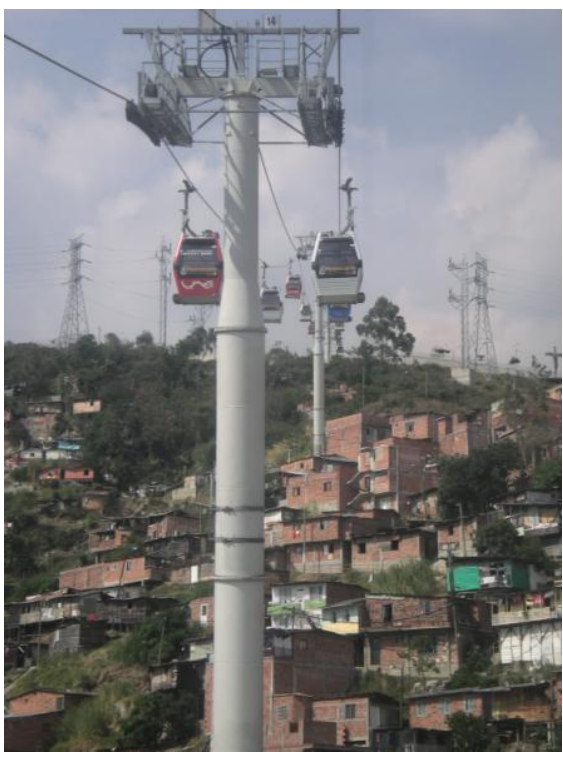

Photo 3: Transfer station San Javier - Lines B and J

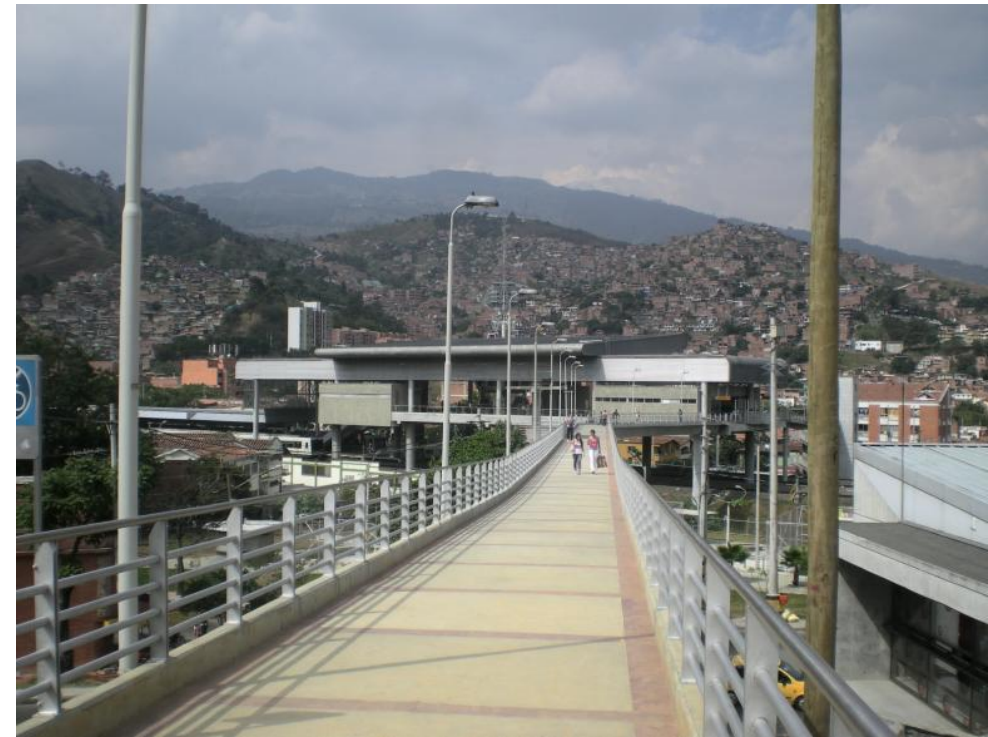




\section{Mobility theory and research methodology}

Our research was motivated above all by an interest in how mobility affects opportunity, and the effects, in the case of Medellín, of how the Metrocable system might contribute to poverty reduction by improving income generation and the living conditions of the surrounding area population.

The importance of mobility in contemporary society has been widely recognized, to such an extent that it has been proposed as a new paradigm for social organization (Urry, 2007), under which mobility has changed from being a luxury to become a generalised necessity and heavy burden; being in movement, real or virtual, has become a demanding and stressful requirement (Bauman, 2000). The luxury nowadays, according to Bauman, consists of being able to escape the obligations of incessant movement. Being able to 'immobilise' oneself has become the act of power of the new elite, which in turn implies an unlimited ability to choose where to be. At the other extreme are the social groups anchored to a particular place through the absolute lack of mobility resources and choice (Zibechi, 2008). As Bauman observes, increased mobility does not homogenise society, rather it stratifies and polarizes, liberating some individuals to act at a distance, free from any spatial ties, whilst imprisoning others in a particular locality.

Much sociological work on mobility has concentrated on the hypermobility of wealthy Western societies and the importance of mobility to economic opportunity and individual freedom, (Ohnmacht et al., 2009; Freundal-Pedersen,2009; Social Exclusion Unit, 2002). In less-developed societies, the poor have a narrow absolute limit to the number of journeys possible because of miserable incomes, which in turn limits their chances of becoming less poor. In his study of the implications of transport costs for people living in the poor periphery of Santiago de Chile, Ureta (2008) found that this peripheral location limited people's ability to travel by foot, at the same time as the high cost of public transport relative to family income restricted people's movement patterns to the strictly essential (work and education). As a consequence, this limited mobility restricted people's participation in urban life in general, and their opportunities to expand work horizons, social and leisure activities, political and civic engagement, and so on. The lack of mobility converts geographical marginalisation into deeper social exclusion.

The lack of mobility becomes an additional form of social inequality. On top of the traditional (vertical) stratification of society according to wealth, income, education and status, mobility develops a 'horizontal' dimension which further fragments and accentuates 
existing social divisions around things like age, gender, ethnicity, lifestyle etc. (Ohnmacht et al., 2007). The young, old, infirm, uneducated become more vulnerable under hypermobility. Moreover, mobility is closely related to leading-edge technology and its appropriation, new forms of surveillance, with important cultural implications in terms of 'creating flows of meaning' and 'cultures of movement' in an everyday sense (Olsen, 2009).

Of course neither transport infrastructures nor social landscapes are flat and uniform. The need to recognise the social and cultural differentiation of contexts led Kaufman et al. (2002, 2004) to consolidate the notion of motility, or the real or potential capacity to be mobile and its significance in different socio-spatial contexts. Mobility, they argue, constitutes a new kind of capital, the appropriation of which requires:

- Access: or the range of possible mobilities according to place, time and other contextual restraints, constrained by options (the systems of transport and communication available) and conditions of that access (costs, logistics, and other restrictions).

- Competences: or the skills and abilities that relate directly or indirectly to access and appropriation, whether physical, cognitive or organizational.

- Appropriation: or how agents (individuals, groups, networks, institutions) interpret and act upon those options; it incorporates needs, plans and aspirations as well as motives, strategies and values.

In applying the Kaufman et al. schemata to the Medellín case, we considered the access factor to be less important than might have been expected. The cable-car system was built in low-income areas with a deficient road infrastructure but relatively well served by conventional buses. However, the cable-car system involved no extra cost for Metro users, and the tariff was only marginally more expensive than buses (and much cheaper than a two bus journey). The logistics of cable system user was more sophisticated and demanding than buses, and considerable effort was made to train users prior to and at the beginning on operations. This can be seen as developing user competences, in terms of the knowledge and skills needed to gain access to the system and use it appropriately. However, such competences are divergent from and often at odds with the more informal skills needed for everyday routines in the 'informal' environments of low-income areas, and this was to be something we needed to be sensitive to.

This leads us to the third aspect of the Kaufmann et al. schema concerning the question of appropriation. The use of the cable-car system was an infrastructural articulation to formal 
urban life, and especially formal sector employment. For social groups outside formal networks or whose everyday routines were circumscribed to the locality, then the level of appropriation could be expected to be much lower, or even antagonistic. Kaufman et al.'s warning as to the different meanings and consequences of mobility options in particular cultural and socio-spatial contexts was to be valuable one. In short, the context of informality, conflict and violence into which the cable systems were retro-fitted, was a key consideration. If poverty conditioned access, informality and conflict could be expected to affect the logics of use and appropriation. The cable cars were also a means of getting the formal sector and state agencies into previously no-go areas - a well known strategy throughout urban history (but little considered among contemporary transport studies).

In short, from the mobility literature and its adaptation to the particular context of the cable-car systems in Medellin, we were able to apply some useful concepts, especially that of motility, in the following terms:

- The need to take into account the double sense of access: for the inhabitants to the rest of the city and for the city authorities to previously no-go areas.

- The need to differentiate between the rationality of the city administration and the logic of the inhabitants of those sectors in terms of everyday survival.

- The need to understand the cable systems as a strategy of normalization of the behaviour and aspirations of 'informal' social organization.

\section{The Medellin Metrocables: mobility impacts and urban improvement potential}

Precise measurement of the impact of the Medellin cable-car systems is difficult for two major reasons. Firstly, as indicated above, impacts are not direct and mechanical, but are determined in relation to a socio-spatial context that is itself constantly changing. Secondly, limited data availability in informal sectors of the city makes even the measurement of trends problematic, let alone the attribution of causality. Thus, for example, estimation of the impact of the cable-cars on the local economy, family incomes or house prices is not only hampered by the lack of official data, but also affected by short-term economic cycles, fluctuation in the level of internal violence, flows of displaced-person immigration, other urban, economic and social programmes, and so on.

Furthermore, the cable-car systems have been implemented in close conjunction with urban improvement projects (PUIs), which makes disentangling the effects of mobility from 
general improvement even more difficult. This applies equally to purely qualitative phenomena, such as the effects of cable-cars/urban improvement on local pride, community self-esteem, the sense of urban integration and social inclusion. In dealing with these challenges and in addition to documentary information, our research adopted an approach similar to that recommended by Flam and Kaufman (2006) using (travel) surveys, focus groups and a variety of interview types in order to achieve an approximation of impacts and an understanding of their nature, and relation to the cable-car systems themselves. Results to date can be summarized as follows:
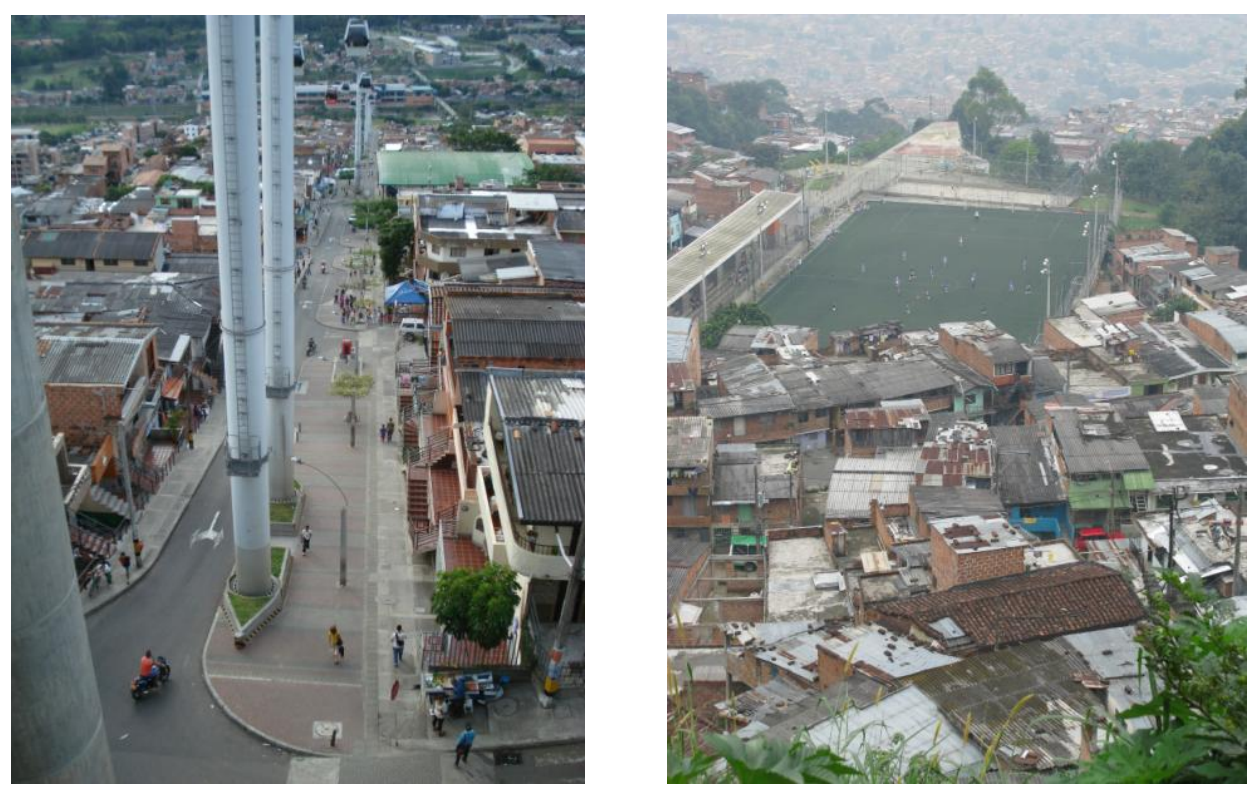

Photos 4 and 5: Urban space improvements, Line K.

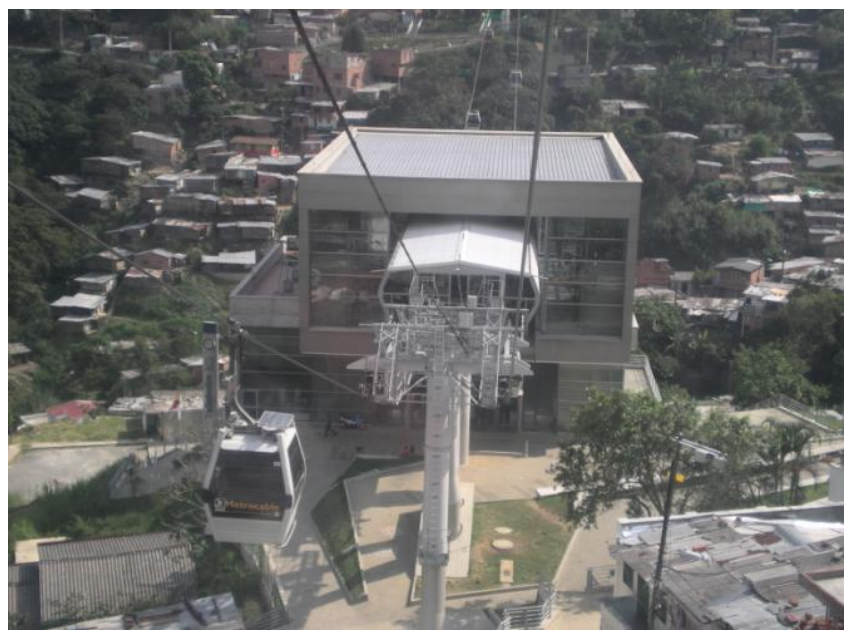

Photo 6: Station, Line J 


\section{Mobility and travel behaviour}

The most obviously expected impact of the cable-cars was improved mobility in terms of shorter journey times and greater comfort. In optimum conditions, Line $\mathrm{K}$, for example, allows a cable-car/Metro journey $10 \mathrm{kms}$ from and 350 metres above the city centre to be undertaken in 20 minutes. However we found that this assumption needs careful qualification. Firstly, access to the cable-car/Metro system can involve lengthy periods of walking and queuing, zero in off-peak but over an hour in peak periods. Secondly, travel patterns need to be taken into account, with the journey to work especially linked to more distant non- city centre destinations. Thirdly, the tariff structure is important. The combined tariff, single ticket involving the cable-car/Metro + bus, makes cable-car use economically attractive for long journeys with a transfer to another mode of transport (savings of 33\% compared to two bus journeys). However, for a non-transfer journey say to the city centre, a conventional bus can be marginally cheaper and quicker once waiting/walking times are taken into account.

A consequence of the above is that the major group of cable-car beneficiaries is formal sector workers (in the construction, manufacturing, services) with long north-south journey to work patterns. Even here, the advantages for these users are more in terms of money than time. The results of a user and non-user survey we undertook are currently being analysed and modeled to determine the relationship between cost, time, comfort and safety as regards modal decision-making for different social groups in the area of influence.

For people in the informal sector of the economy (the great majority), children and young people, housewives, the elderly and infirm, the cable-car/Metro system offers much more restricted advantages and therefore more limited use. Less than $10 \%$ of the journeys in the area of influence (as defined by local administrative boundaries) use the cable-car/Metro, conventional buses and walking continue to be the major transport modes, and there is little evidence to suggest an increase in the number of journeys made for non-essential trips leading to greater participation in city life.

\section{Mobility and the local economy}

A second major expectation concerned the positive effects of improved mobility on the economic condition of the zones of influence and the livelihoods of the inhabitants. It was supposed that better public transport options and greater accessibility would facilitate citywide employment opportunities for local residents, as well as invigorate the local economy in 
terms new businesses, more (formal sector) employment, increased building activity, livelier land and housing markets, and so on.

Once again, the evidence to date indicates only modest changes in this respect. While it is true that in the immediate vicinity of the stations and where urban improvements have been undertaken below the overhead cables, the number of shops, bars and restaurants, workshops and small-businesses has increased significantly. However, outside these tightly defined areas, neither small-scale economic activity nor house prices or rents appear to show important changes. In the second system, Line J, where the stations are less well articulated to urban morphology and street patterns, these types of benefits are still less evident.

Advice bureaux for small business have been established in the community centres (park-libraries) close to each of the cable-car systems, backing up better mobility with technical and financial services for business set-ups. However, poor connection to city-wide institutions and markets, and limited finance programmes, have restricted the scope of new small businesses to micro-scale enterprises and neighbourhood markets with little prospect of sustained growth which might impact on the poverty and inequality currently affecting the city (Bateman et al., 2011).

From 2004 onwards there was an increase in the number of formal property transactions in the areas of influence of both cable-car lines, but this reflected a general trend across the city. The quality of life index for the areas of influence of the cable-cars showed unstable trend while the human development index showed a general improvement since 2004. Interestingly, neither of these indices includes a measurement of mobility.

\section{Urban improvement, social inclusion and citizenship}

As was mentioned earlier, the cable-car systems have been accompanied by so-called Integral Development Projects (PUIs in their Spanish acronym). The philosophy behind these projects is that better mobility is only a part of area regeneration in the deprived sectors of the city, and that transport infrastructure needs to be complemented by improvements in housing, schools, the environment and public space if wider and sustained improvements are to be achieved. The first PUI was developed around the first cable-car line (Line K) and since then three other s are being implemented in strategic areas of the city. Another important aspect is that of high quality architecture which inspires community pride, self-esteem and a sense of belonging” (Alcaldía de Medellín, 2008). 
This was, in the course of events, to become known as "social urbanism", a key aspect of the 'Medellín model' of good urban governance recognized by the Organisation of American States and many other urban development and architectural bodies. It was hoped this adaptation of the Barcelona model of urban intervention would lead to a 'profound social transformation' and a 'new social contract' in the deprived and violent sectors of the city, on the basis of 'spaces for citizenship'and 'settings for democracy and peaceful cooexistence' (Alcaldía de Medellín, 2008). Within this radical political agenda, our research suggests that questions of age and gender equality and access for the disabled are only recent concerns.

Our research confirms the increase in community self-esteem and the sense of inclusion that the cable-car systems and urban projects have produced. The great majority of residents is proud of what has happened in their communities and are welcoming to visitors and tourists; once stigmatized, they now feel part of the city. However, Medellin's version of 'social urbanism' has not been without criticism. The early projects were highly participative, recent ones much less so; concerns have been raised about future maintenance costs; the architecture has been criticized for its plagiarism and ostentation; some argue that the city administration has been carried away, literally, with its own success, has overstretched its resources and is now more concerned with constructing an image than transforming reality.

\section{Political significance}

The creation, via the cable-cars and associated urban improvements, of a sense of inclusion is an important political benefit, in both an internal and external sense. City administrations gain in legitimacy and governability vis-a-vis the urban population, whilst the aesthetic impact of cable-cars and high-quality architecture in poor urban areas fascinates the architectural profession and can be used to promote an economically competitive and socially progressive image. The attraction of cable-car systems for city mayors, including those of Rio de Janeiro and London, is easy to understand.

In contrast to the modest impacts in terms of increased mobility and material wellbeing, the cable-car systems can be seen as having an enormous symbolic significance. Architectural and engineering gestures, aesthetic experience and sensation determine the political response of neighbourhood residents and external visitors alike. Adroit manipulation of the symbolic world, especially in the context of contemporary urbanism of the spectacle, is undoubtedly important and effective. 
The cable-car systems can also be understood as dispositives for the normalisation of informal sectors of the city. The cable cars carry with them social norms, strictly enforced rules of behaviour, everyday surveillance, heavier policing, administrative procedures, information registers, and so on. Most residents accept this as something positive or at least necessary, although it does provoke a degree of discomfort, inconformity, and resistance. As a form of social control it fails to reach illegal (rather than informal) social groups and organisations, for whom a parallel strategy of repression is being implemented in those same sectors.

Finally, the Medellin experience is a timely reminder of the unique capacity and ultimate responsibility of the public sector - public institutions, public investment and staterun enterprises - with regard to urban improvement in the poor areas of cities.

\section{Conclusions}

The success of the first cable-car line in Medellin (Line K) was such that it made the implementation of such a system look easy. The second line (Line K) made clear that such infrastructure requires careful and systematic integration into social and spatial networks in order to ensure that increased mobility results in more generalised urban improvement. In this respect, it is important to underline the fact that investment in complementary urban improvement projects was around six times the cost of the cable-car system itself, not including the cost of the social programmes undertaken in the area.

But even there doubts remain as to the wider effects of greater mobility through cablecars. They are used by a minority of residents (less than 10\%), complementary urban and architectural spaces probably less still; benefits for the local economy have been limited, and land and housing market stimulus has been restricted to the immediate environs of the cable lines. Even so, these benefits should not be undervalued, given the relatively low cost of the cable-car systems themselves.

However, the greatest benefits accrue around the symbolic value of cable-car systems. These highly visible infrastructures and the aesthetic experience they afford to both residents and visitors, create sensations of social inclusion and integration into the modern city, and develop local pride and promote individual self-esteem. It does, however, raise the question of how long this can be maintained without support through economic growth which reduces poverty and inequality, and incorporates citizens into democratic urban life in a more 
systematic way. The spectacular nature of the aesthetics of the cable-car systems loses its appeal against a backdrop of unmitigated poverty.

Whatever the case, other cities considering the implementation of cable-car systems need to ensure the satisfaction of the basic conditions of (i) a topography and morphology which inhibit more conventional and higher capacity public transport systems, (ii) relatively consolidated housing areas where qualitative improvement is possible, and (iii) the need for governance structures which facilitate rapid and coordinated implementation. Cable-car systems in Medellin have been successful (in transport, urban and social terms) to the extent that they form part of a concerted policy of integrated improvement of low-income areas. Against all prima facie visual evidence, the quick fix approach motivated by short-term political impact and publicity-conscious gain are unlikely to be successful.

\section{References:}

Bateman, M., Duran J-P, and Maclean, K. (2011) A Post-Washington Consensus Approach to Local Economic Development in Latin America? An Example from Medellín, Colombia, Background Note, London: Overseas Development Institute - available from www.odi.org.uk Bauman, Z. (2000) Liquid Modernity, Cambridge: Polity.

Blanco, C. and Kobayashi, H. (2009) 'Urban transformation in slum districts through public space generation and cable transportation at northeastern area: Medellín, Colombia', The Journal of International Social Research, Vol. 2, No.8: 75-90.

Brand, P. (2005) Urban Environmentalism: Global Change and the Mediation of Local Conflict, London: Routledge.

Brand, P. (2010) 'El urbanismo social de Medellín, Colombia', $a *$ - Revista de Arquitectura - COAM, (Colegio Oficial de Arquitectos de Madrid), No. 359, 99-103.

Cañon, L. (2010) Transport and social exclusion in Medellín. Potential, opportunities and challenges, MA dissertation, Development Planning Unit, University College London, London.

Davila, J. (2009) 'Being a mayor: The view from four Colombian cities', Environment and Urbanization, Vol. 21, No. 1, 37-57.

Echeverri, A. and Orsini, F. (2010) 'Informalidad y urbanismo social en Medellín' (Informality and social urbanism in Medellín), in M. Hermelin, A. Echeverri and J. Giraldo (Eds) Medellín: Medio Ambiente, Urbanismo y Sociedad, Medellin: Universidad EAFIT.

El Tiempo (2011) 'Medellín aún desconoce desplazados intraurbanos por conflicto', ('Medellin fails to recognise intra-urban displaced persons'), 8 May 2011, available from http://www.eltiempo.com/colombia/medellin/ARTICULO-WEB-NEW_NOTA_INTERIOR-

Freudendal-Pedersen, M. (2009) Mobility in Daily Life: Between Freedom and Unfreedom, Farnham: Ashgate.

Fukuyama, F. and Colby, S. (2011) 'Half a Miracle: Medellín's rebirth is nothing short of astonishing. But have the drug lords really been vanquished?', Foreign Policy, available from - www.foreignpolicy.com/articles/2011/04/25/half a miracle

Kaufmann, V. (2002) Re-thinking Mobility, Aldershot: Ashgate.

Kaufmann, V., Bergman, M. and Joye, D. (2004) 'Motility: Mobility as Capital', International Journal of Urban and Regional Research, Vol. 28, No.4: 745-756.

Kenyon, S., Lyons, G. and Rafferty, J. (2006) 'Social exclusion and transport in the UK: a role for virtual accessibility in the alleviation of mobility-related social exclusion?', Journal of Social Policy, Vol.32, No.3: 317-338.

Flamm, M. and Kaufmann, V. (2006) 'Operationalising the concept of motility: a qualitative study', Mobilities, Vol.1, No.2: 167-189. 
Jensen, O. (2009) 'Flows of meaning, cultures of movement - urban mobility as meaningful everyday practice', Mobilities, Vol.4, No.1: 139-158.

MacDonald, K. and Grieco, M. (2007) 'Accessibility, mobility and connectivity: the changing frontiers of everyday routine", Mobilities, Vol.2, No.1: 1-14.

MacNamara, E. (2009) Strengthening the community with culture in Medellín through Park-Library San Javier, MA Dissertation, Bartlett School of Architecture, University College London: London.

Medellin - Alcaldía (2008) Medellín: La Transformación de una Ciudad, Medellín. Medellin - EDU (2011) Proyectos Urbano Integrales - PUIs, available from - www.edu.gov.co (also in English)

Ohnmacht, T., Maksim, H., and Bergman, M. (2008) Mobilities and Inequality, Farnham: Ashgate.

Quinchía, S. (2011) Discursos y prácticas de planeación: el caso del urbanismo social de Medellín, Colombia, MA dissertation, School of Urban and Regional Planning, Universidad Nacional de Colombia, Medellín.

Social Exclusion Unit (2002) Making the Connections: Transport and Social Exclusion, available at - www:cabinet-office.gov.uk/seu/publications

The Architectural Review (2011) Special Issue: Recent Work in Colombia. How architecture is healing the public realm. A tale of two cities - Bogotá and Medellín, Vol.CCXXIX, No. 1368.

Ureta, S. (2008) 'To move or not to move? Social exclusion, accessibility and daily mobility among the low-income population in Santiago, Chile', Mobilities, Vol.3, No.2: 269-289.

Urry, J. (2007) Mobilities, Cambridge: Polity.

Zibechi, R. (2008) América Latina: Periferias Urbanas, Territorios en Resistencia, (Latin America: Urban Peripheries, Territories of Resistance), Bogotá: Ediciones Desde Abajo. 